\title{
ANÁLISE AVANÇADA DO CAPITAL DE GIRO
}

\author{
Autor: Roberto Braga \\ Professor-assistente Doutor do Departamento \\ Contabilidade e Atuaria da Faculdade de Economia, \\ Administração e Contabilidade da USP
}

\section{ANÁLISE AVANÇADA DO CAPITAL DE GIRO}

A administração do capital de giro constitui um processo de planejamento e controle dos recursos financeiros aplicados no ativo circulante das empresas. Esses recursos provêm de diversas obrigações a vencer em curto prazo, representadas no passivo circulante, e do excedente das exigibilidades de longo prazo e do patrimônio liquido em relação aos ativos não circulantes.

A gestão do capital de giro é extremamente dinâmica exigindo a atenção diária dos executivos financeiros. Qualquer falha nesta área de atuação poderá comprometer a capacidade de solvência da empresa e/ou prejudicar a sua rentabilidade.

Este trabalho foi dividido em duas grandes partes. A primeira inicia com a análise dos prazos médios de estocagem, de cobrança e de pagamentos para chegar ao calculo da duração dos ciclos operacionais, econômico e financeiro e dos montantes de recursos necessários ao financiamento dos mesmos. Na segunda parte é apresentada uma metodologia introduzida no Brasil pelo Professor francês Michel Fleuriet (1) que atuou há alguns anos na fundação Dom Cabral, em Belo horizonte, MG. Essa metodologia permite avaliar rapidamente a situação financeira das empresas através da classificação dos balanços em um dos seis tipos possíveis de configurações de determinados elementos patrimoniais. Trata-se um passo adiante em relação ao esquema tradicional de análise de balanços feito através de índices econômico-financeiros.

Apesar de alguns estudiosos brasileiros haverem reproduzido esta metodologia em livros didáticos e em trabalhos acadêmicos, julgamos que a mesma ainda não foi suficientemente difundida nosso pais. Desta forma, julgamos oportuno apresentar a nossa versão sobre este assunto.

1. A mensuração dos recursos aplicados nas operações

1.1 Prazos médios

A análise dos recursos investidos no giro das operações de uma empresa envolve o calculo dos prazos médios de renovação dos estoques, de cobrança das duplicatas a receber e de pagamento das compras de materiais de produção e/ou de mercadorias para revenda. Esses prazos médios costumam ser calculados para períodos anuais, embora também possam se-lo para intervalos de tempo menores.

Vejamos inicialmente quais são os elementos envolvidos na movimentação dos estoques de uma empresa industrial.

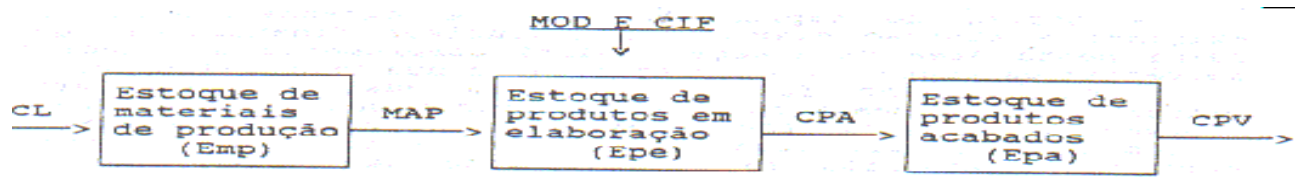

As entradas nos estoques de matérias-primas e de outros materiais utilizados no processo industrial (Emp) são contabilizadas pelo valor das compras liquidas dos impostos $(\mathrm{CL})$.

Os materiais aplicados na produção (MAP), correspondem às saídas destes estoques, valorizadas pelos preços médios. O valor das compras liquida pode ser obtido através do seguinte cálculo: 
juntos com outros que tiveram rotação mais lenta, 120 dias por exemplo. A média ponderada dos valores desses itens foi que determinou o prazo médio de 60 dias.

Sob condições inflacionárias, todos os valores envolvidos nestes cálculos devem ser primeiramente corrigidos para o poder aquisitivo da moeda em uma mesma data.

A movimentação dos estoques de mercadorias para revenda nas empresas comerciais envolve: compra liquida do ICMS nas entradas $(\mathrm{CL})$ e o custo das mercadorias vendidas nas baixas (CMV).

Conhecendo os saldos dos estoques iniciais (Elmr) e final (EFmr) das mercadorias para revenda e o CMV, pode-se determinar diretamente o valor das compras liquidas:

$\mathrm{CL}=\mathrm{Efmr}-\mathrm{Eimr}+\mathrm{CMV}$.

As compras brutas são determinadas como segue:

$\mathrm{CB}=\mathrm{CL} /(1-$ alíquota do ICMS).

O prazo médio de estocagem das mercadorias para revenda (PMEmr) utiliza em seu calculo o saldo médio do estoque de mercadoria (Sm Emr) e o CMV.

Preço médio de estocagem das mercadorias ou período médio de vendas (PMV):

$\mathrm{PMEmr}=\mathrm{Sm} \mathrm{Emr \times 360 \text {dias }}$
$-\mathrm{CMV}$

No calculo de prazo médio de cobrança (PMC) são considerados: o saldo médio das duplicatas a receber (Sm DR) e a receita operacional bruta deduzida do valor das devoluções e abatimentos (ROB - DA).

Prazo médio de cobrança das duplicatas a receber :

$\mathrm{PMC}=$

$$
\begin{gathered}
\mathrm{Sm} \text { DR } \times 360 \text { dias } \\
\hline \mathrm{ROB}-\mathrm{DA}
\end{gathered}
$$

O PMC envolverá as vendas a vista e a prazo quando for utilizado o faturamento total no denominador obtem-se o prazo médio de recebimento das vendas a prazo, inclusive os atrasos ocorridos nas liquidações das duplicatas. As devoluções e os abatimentos devem estar compatibilizados com o critério adotado para o calculo do PMC (Total ou apenas relativo ás vendas a prazo).

O Prazo médio de pagamento das compras de materiais de produção e/ou das mercadorias para revenda, também conhecido por prazo médio de pagamento das compras dos fornecedores (PMPf) considera em seu cálculo o saldo médio das duplicatas a pagar (Sm DP) e o valor das compras (Sm DP) e o valor das compras brutas (CB), cuja determinação foi demonstrada anteriormente.

Prazo médio de pagamento dos fornecedores:

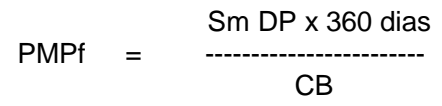

Da maneira como foi apresentado, o PMPf incluirá também as compras a vista.

\subsection{Ciclos operacionais, econômicos e financeiros}

O Ciclo operacional (CO) corresponde ao intervalo de tempo compreendido desde a recepção dos materiais de produção (ou das mercadorias para revenda) até a cobrança das vendas correspondentes. Durante esse período são investidos recursos nas operações da empresa sem que ocorram as entradas de caixa de relativas as vendas. Parte deste capital de giro é suprida pelos fornecedores que concederam prazo para pagamento das compras de materiais ou de mercadorias . Utilizando os prazos médios para representar os ciclos operacionais das empresas industriais e das empresas comerciais (COi) e das empresas comerciais.

Coi $=$ PMEmp + PMF + PMV + PMC
Coc $=$ PMEmr + PMC 
O ciclo econômico está contido no ciclo operacional: inicia com a recepção dos materiais de produção (ou das mercadorias para revenda) e termina com a saída dos produtos (ou das mercadorias) vendidas. O ciclo econômico desconsidera os aspectos financeiros concernentes aos pagamentos das compras e a cobrança das vendas.

Representando os ciclos econômicos das empresas industriais (CEi) e das empresas comerciais (CEc) através dos prazos médios, tem-se

Cei $=$ PMEmp ++ PMV

$\mathrm{Cec}=\mathrm{PMEmr}$

O ciclo financeiro compreende o prazo entre as saídas de caixa relativas aos pagamentos dos fornecedores e as entradas de caixa provenientes dos recebimentos das vendas. Durante este período, a empresa tem de financiar suas operações sem a participação dos fornecedores. Quanto maior for o ciclo financeiro, mais de recursos próprios e de terceiros (exeto de fornecedores) estarão temporariamente aplicados nas operações, provocando custos financeiros e afetando a rentabilidade.

Novamente pode-se recorrer aos prazos médios para representar os ciclos financeiros das empresas industriais (CFi) e das empresas comerciais $(\mathrm{CFc})$.

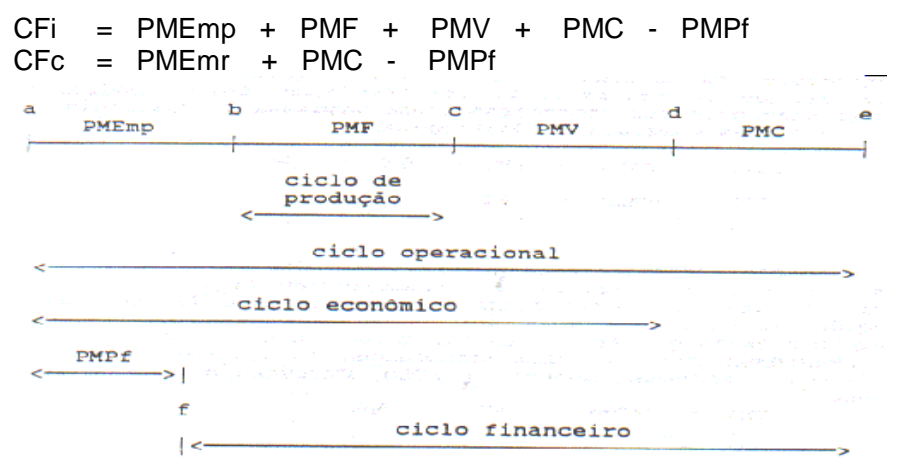
(a) = recepção dos materiais de produção
(b) = início da produção
(c) = término da produção
(d) = venda dos produtos
(e) = cobrança das duplicatas
(f) = pagamento dos fornecedores

\subsection{Exemplo do calculo dos prazos médios e dos ciclos}

O exemplo a seguir refere-se a um grande grupo industrial que fabrica calçados, fios, tecidos, artigos de vestuário, artigos esportivos e materiais de embalagem. Os dados utilizados foram extraídos das suas demonstrações financeiras consolidadas publicadas na imprensa. Apresentados em \$ mil, todos os valores estão expressos em moeda de 31q/dez/t9 que corresponde à data do ultimo balanço. 


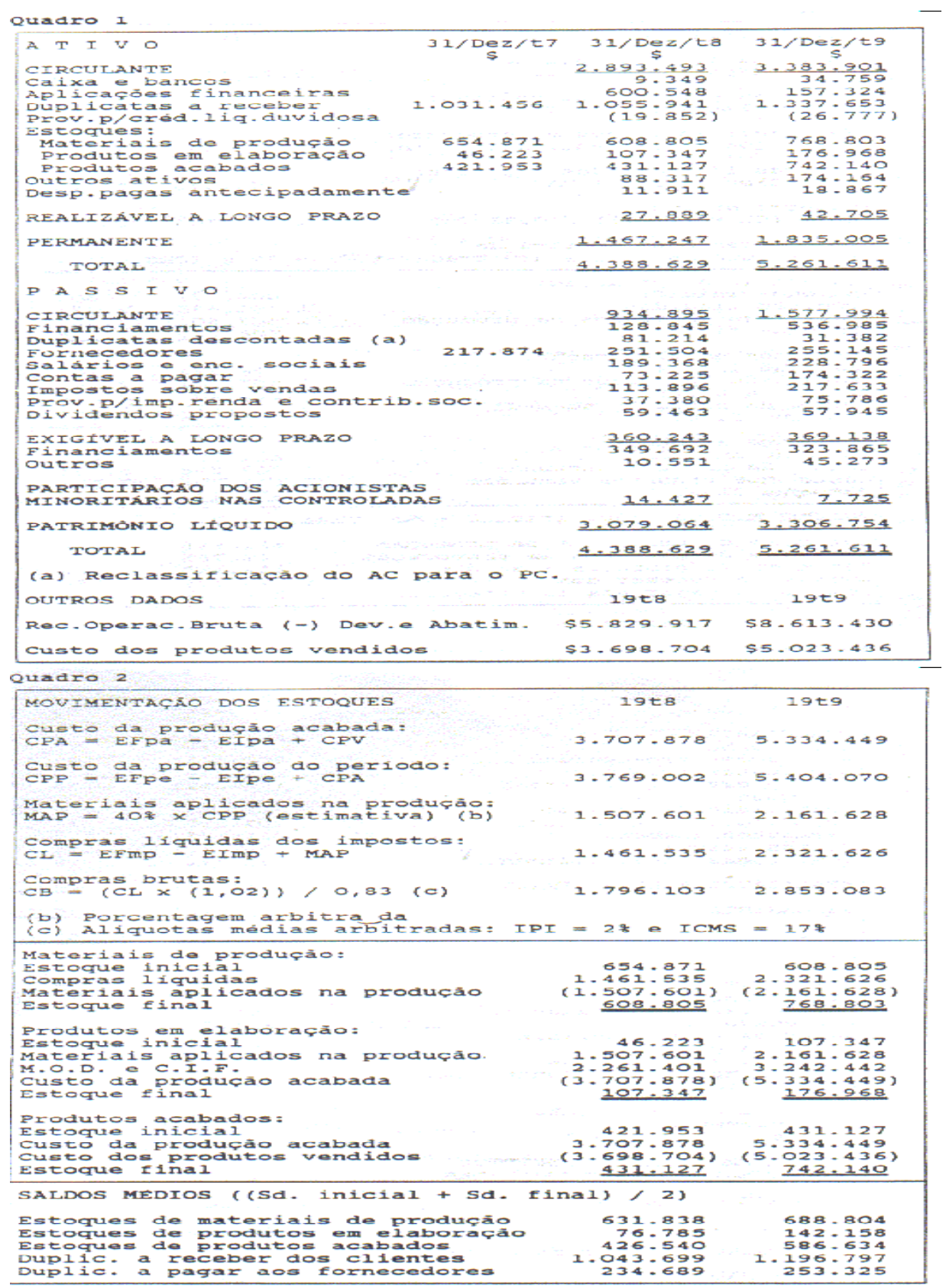




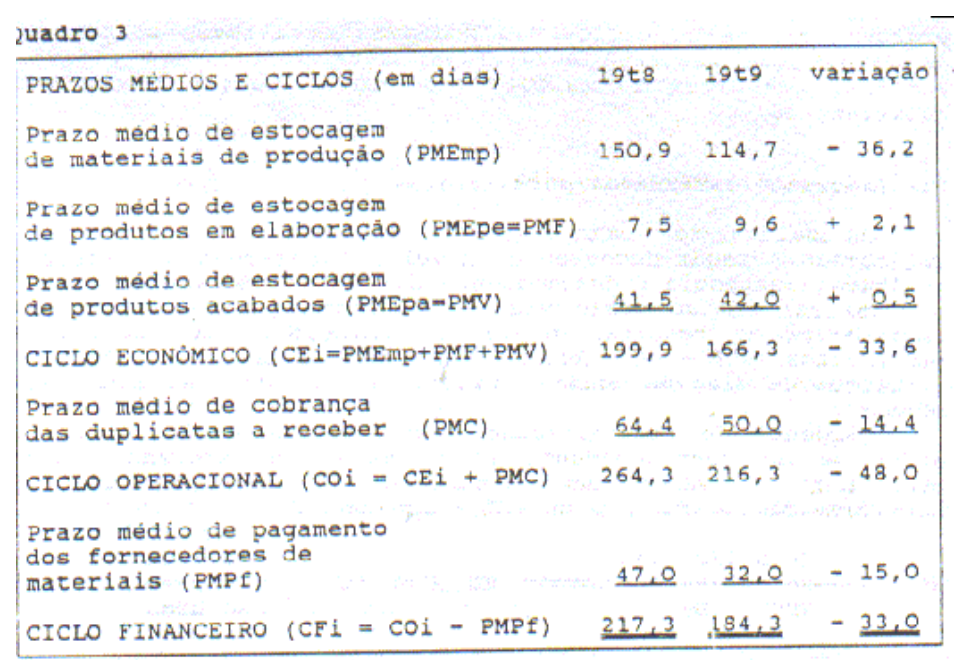

Confrontando o último exercício social com o anterior, verifica-se que a queda do PMEmp, determinou a redução de 33,6 dias no ciclo econômico. Essa redução, aliada a queda do PMC, fez com que o ciclo operacional declinasse 48 dias.

O PMPf apresentou uma redução ligeiramente superior a do PMC. Com isto o ciclo financeiro foi 33 dias menor do que a do ano anterior.

Constata-se então que o menor ciclo financeiro observado em 19 t9 basicamente determinado pela redução do PMEmp.

Salvo quando ao fato destes prazos médios terem sido calculados a partir da média dos saldos inicial e final e não a partir das médias dos saldos mensais de cada exercício social, pode-se considerar que a duração de cada ciclo está correta em termos, de medida do tempo médio. Entretanto, deve-se atentar para o conteúdo dos diferentes tipos de saldo computados, a saber:

Os saldos dos estoques dos materiais de produção são valorizados pelos preços médios das compras liquidas dos impostos.

Além das compras liquidas, os saldos dos estoques de produtos em elaboração e de produtos acabados contém custos de Mão-de-obra direta e custos indiretos de fabricação;

O saldo das duplicatas a receber é formado pelo custo dos produtos vendidos e pelo lucro bruto; e

O saldo das duplicatas a pagar aos fornecedores representa as compras brutas, com o IPI e ICMS, ainda não liquidas.

Assim, conclui-se que, da maneira como foram calculados, os prazos médios e os ciclos não podem ser avaliados conjuntamente em termos dos recursos envolvidos. Esta dificuldade poderá ser contornada através do calculo dos prazos médios e dos ciclos equivalentes.

\subsection{Recursos Demandados pelos ciclos}

Os saldos dos estoques, das duplicatas a receber e das duplicatas a pagar decorrem do nível de operações da empresa que em última estância é determinado pelo volume de vendas.

No calculo do prazo médio de cobrança (PMC) utiliza-se no denominador as receitas de vendas diminuídas das devoluções e abatimentos (ROB - DA.). ASSIM, O pmc pode também ser interpretado em termos de dias de vendas mantidos sob a forma de duplicatas a receber.

Dispondo de uma projeção das receitas médias diárias de vendas e do correspondente prazo médio de cobrança, pode-se determinar o saldo das duplicatas a receber através da transformação da formula do PMC, como segue:

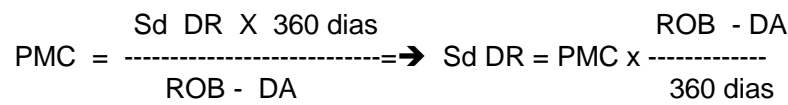

Onde, "Sd DR" representa o saldo das duplicatas a receber, podendo ser o saldo médio (Sm) ou o saldo final (Sf) do período. 
Os prazos médios prazos de estocagem (PMEmp, PMEpe e PMEpa) e de pagamento (PMPf) necessitariam ser convertidos para o seu equivalente em dias de vendas para que pudessem ser comparados entre si e com o PMC em termos dos recursos envolvidos. Com isso ter-se-ia prazos médios equivalentes para a estocagem dos materiais de produção (PMeEmp), dos produtos em elaboração (PMeEpe), dos produtos acabados (PMeEpa) e para os pagamentos dos fornecedores (PMePf) a saber:

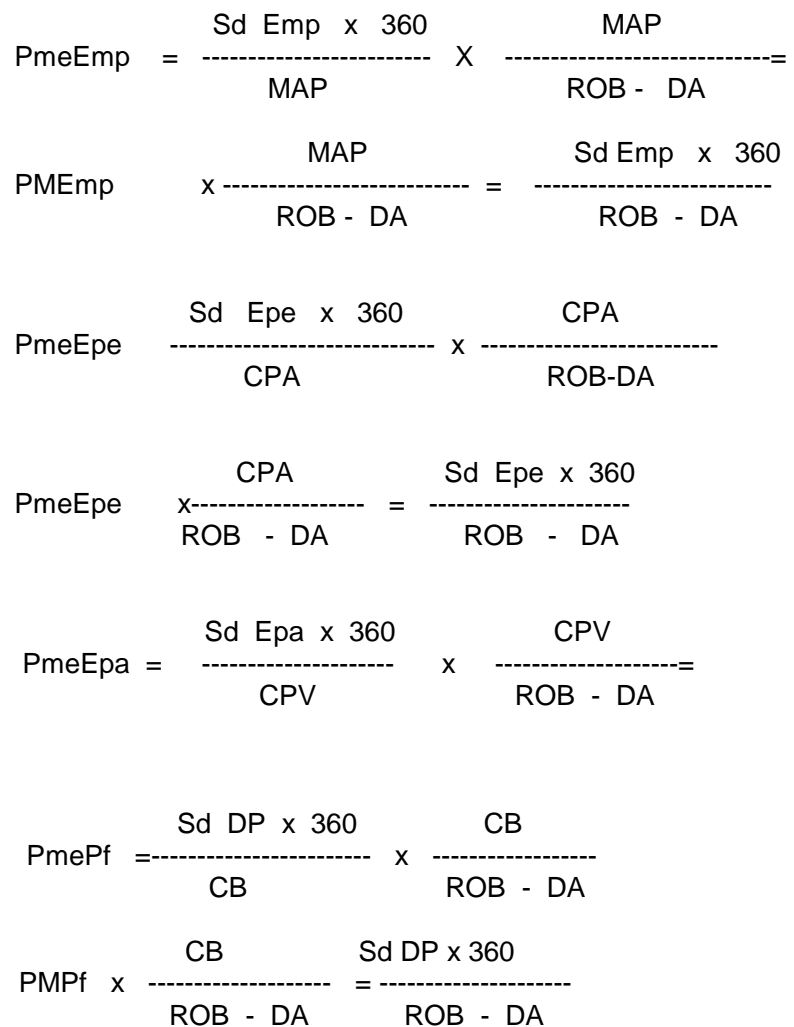

Onde, (MAP/ROB - DA), (CPA/ROB - DA) E (CB/ROB - DA) Constituem os fatores de conversão de períodos de tempo efetivos para dias de vendas.

Multiplicando os dias de venda (fornecidos pelo calculo dos prazos médios equivalentes) pela receita média seria de vendas, encontra-se o valor dos recursos investidos nos saldos (médios e finais, conforme se deseje) dos estoques, bem como o valor dos financiamentos concedidos pelos fornecedores de materiais de produção.

O PMC não precisa ser convertido porque já expressa dias de venda.

O prazo médio equivalente de estocagem das mercadorias para revenda (PMeEmr) é obtido de forma idêntica ao PmeEpa, bastando substituir a formula o "Sd Epa" e o "CPV" por "Sd Emr" e "CMV", respectivamente.

Dispondo dos prazos médios equivalentes, calcula-se os dias de venda correspondente ao ciclo operacional equivalente (CFe). Multiplicando esses dias de vendas pela receita média diária de vendas obtem-se os montantes de recursos envolvidos em cada um dos mencionados ciclos.

Para demonstrar o emprego das fórmulas dos prazos médios equivalentes, serão utilizados alguns dados extraídos do exemplo apresentado anteriormente, admitindo que os mesmos fossem projeções feitas no final de 19t8, relativas ao exercício social em 1979 .

A partir dessas projeções deseja-se saber quais serão os montantes de recursos aplicados, no final de 1979, nos estoques e nas duplicatas a receber, bem como o saldo a pagar aos fornecedores na mesma época. Trabalharemos com 6 casas decimais para nos aproximar ao máximo dos saldos constantes do balanço apresentado no Quadro 1 que correspondem ás respostas desejadas. 
Conforme demonstrado no quadro 4, todos os saldos determinados a partir dos prazos médios equivalentes foram idênticos àqueles que se desejava obter e que constam do balanço de 31/Dez/79 apresentado no quadro 1 .

Alguns poderão alegar ser difícil projetar as proporções do MAP, CPV, e CB sobre as receitas das vendas. A solução é simples, embora trabalhosa. Deve-se começar a partir das proporções verificadas no ultimo exercício social e fazer os ajustes relativos às alterações esperadas no "mix" de produjtos e/ou de materiais, nas variações reais nos preços de compra e de venda etc.

Obviamente, esse modelo deve estar orientado para as operações futuras e dispensará o uso de tantas casas decimais como foi necessário no exemplo para encontrar os saldos previamente conhecidos.

O modelo tornar-se-ia ainda mais valioso na medida em que se faça simulações para avaliar os impactos sobre o capital de giro decorrentes de aumentos ou reduções na receita de vendas, nos prazos médios e nos fatores de conversões dos sias efetivos para dias de vendas.

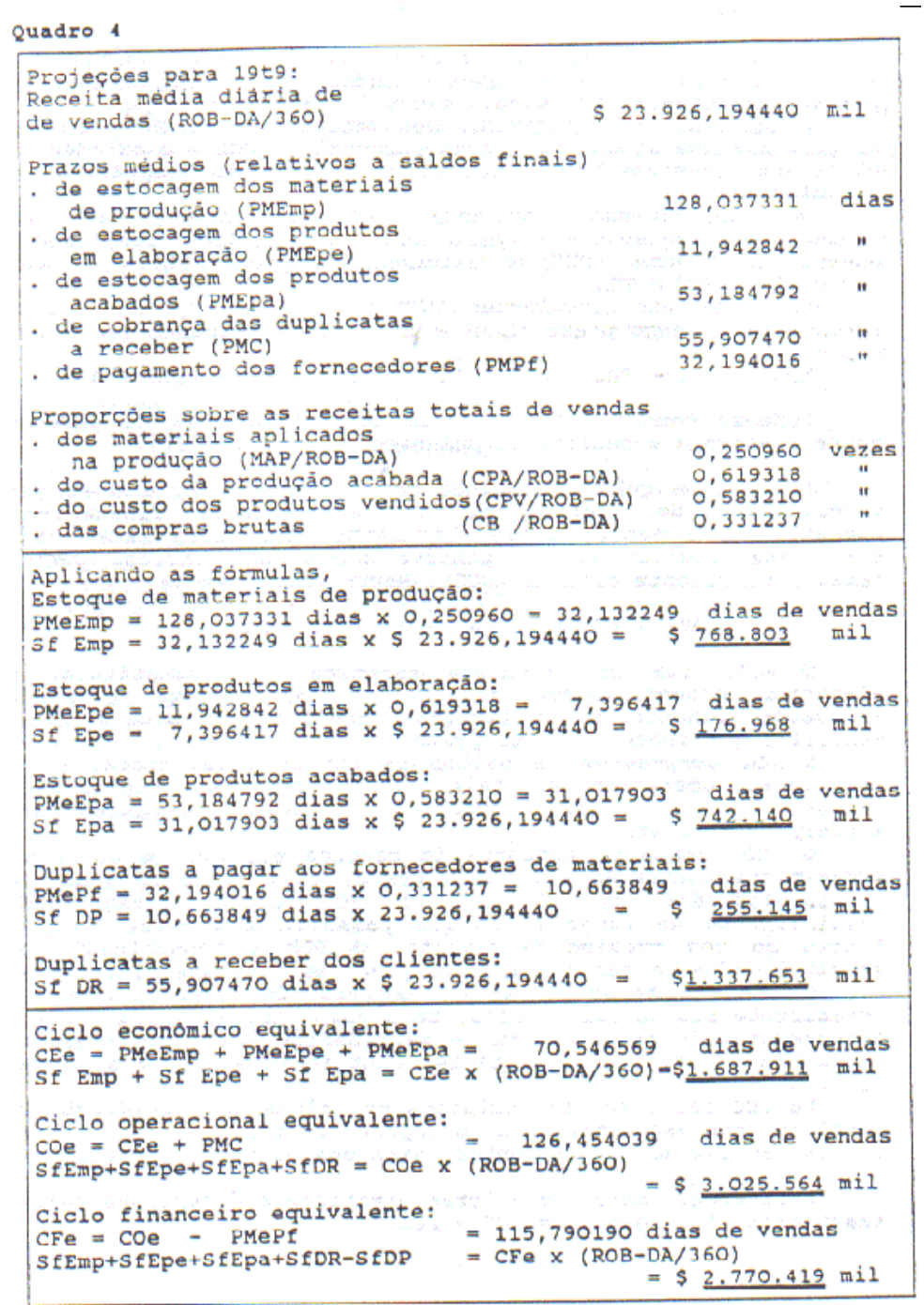

\section{A Dinâmica a Situação Financeira}

O capital de giro corresponde aos recursos aplicados pelo ativo circulante (AC) e esses recursos são constituídos pelo passivo circulante (PC) e pelo capital circulante e pelo capital circulante liquido (CCL).

O CCL representa a parcela dos recursos permanentes aplicadas no giro das operações. Em outras palavras, o CCL é o excedente do total dos passivos não circulantes em relação aos ativos não circulantes. 
Os passivos não circulantes (PNC São constituídos pelas contas que integram o exigível em longo prazo (ELP), resultados de exercícios futuros (REF) e patrimônio liquido $(\mathrm{PL})$, ou seja, $\mathrm{PNC}=\mathrm{ELP}+\mathrm{REF}=\mathrm{PL}$.

Os ativos são circulantes (ANC) são formados pelas contas do realizável em longo prazo (RLP) e do ativo permanente (AP). Logo, ANC = RLP + AP.

Então, $C C L=A N C-A N C=(E L P+R E F+P L)-(R L P+A P)$.

Pode-se também obter o valor do CCL através da diferença entre o ativo e o passivo circulantes $(C C L=A C-P C)$.

$\mathrm{Na}$ análise que se pretende desenvolver, o $A C$ e $~ O P C$ serão subdivididos de acordo com a sua natureza financeira e operacional, a saber: Ativo circulante financeiro (ACF), ativo circulante cíclico (ACC), passivo circulante oneroso (PCO) e passivo circulante cíclico (PCC). Deste modo, tem-se

O ACF, tem uma natureza errática e é constituído por elementos essencialmente financeiros como caixas e bancos, aplicações financeiras e liquidez imediata e títulos e valores mobiliários a vencer em curto prazo.

O ACC compreende os saldos de contas relacionadas com as atividades operacionais, tais como: estoques, duplicatas a receber, provisão para devedores duvidosos, despesas pagas antecipadamente etc.

O PCO também se comporta de maneira errática e abrangem os empréstimos contratados em curto prazo, as duplicatas descontadas (reclassificadas do AC para o PC) e os financiamentos originalmente de longo prazo que passaram a constar no PC em função do seu próximo vencimento. O PCO é constituído pelas exigibilidades de curto prazo que provocam despesas financeiras.

O PCC é formado pelos passivos em funcionamento que normalmente são de curto prazo, tais como: duplicatas a pagar, impostos, taxas, contribuições e contas a pagar diversas.

No PCC serão também incluídos os saldos dos dividendos, das participações estatutárias e do imposto de renda a pagar sobre os lucros, apesar destes elementos terem uma natureza errática.

A diferença entre os valores erráticos é denominada saldo de tesouraria ( $T$. Logo, $T=A C F$ - PCO).

A diferença entre os valores cíclicos é conhecida por necessidade de capital de (NGG), conforme Fleuriet, ou por investimento operacional em giro (IOG), denominação adotada por silva (2). Então, o IOG (Ou NCG) = ACC - PCC.

Assim, foram identificados os seguintes elementos:

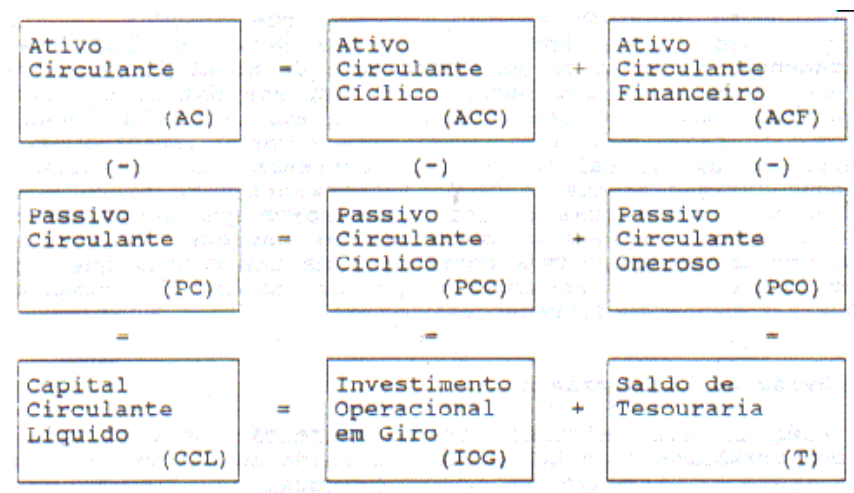

Pode-se encontrar valores positivos ou negativos para o CCL, o IOG e o T. Apenas por mera coincidência seria encontrado valor zero para alguns destes elementos.

\subsection{Investimento Operacional em Giro (IOG)}

A magnitude do ICC decorre basicamente do volume dos estoques e dos saldos das duplicatas a receber, uma vez que as demais contas que poderiam ser encontradas no ACC normalmente apresentam saldos de pequena monta.

Elevada a soma de recursos aplicados nos estoques decorre isolada ou simultaneamente, dos volumes das operações da empresa (compras, produção e vendas) na duração do ciclo de produção e do prazo médio de venda (PMV).

Os recursos aplicados em duplicatas a receber são determinados pelo volume das vendas a prazo pelo prazo médio de cobrança (PMC) que é afetado pelo prazo concedido no faturamento e pelas duplicatas vencidas e não liquidadas. 
O PCC decorre do volume de compras (de materiais de produção ou de mercadorias para revenda), conjugado com o prazo médio de pagamento para os fornecedores. As demais contas do PCC (salários, encargos sociais e outras contas a pagar) poderão apresentar ou não saldos expressivos que, em sua maioria, costumam a vencer em curtíssimo prazo.

Correspondendo a diferença entre o ACC, e o PCC, o IOG é fundamentalmente determinado pelo nível das atividades operacionais da empresa e pelos preços médios de estocagem, de cobrança e de pagamento dos fornecedores e das demais despesas operacionais.

Fleuriet diz que a necessidade de capital de giro (NCG ou IOG é muito sensível às modificações que ocorrem no ambiente econômico em que a empresa opera. A NCG (ou IOG) depende, basicamente, da natureza dos negócios ou de nível de atividades da empresa. A natureza dos negócios da empresa determina seu ciclo financeiro, enquanto que o nível de atividades é função das vendas. O nível de atividades afeta mais acentuadamente a necessidade de capital de giro das empresas com ciclo financeiro de longa duração do que as do ciclo financeiro de curta duração.

As contas cíclicas do ativo e passivo que determinam o NGG (ou IOG) estão ligadas as operações da empresa. De modo geral essas conta representam a contrapartida das contas que formam o lucro operacional (resultado apurado antes de computar as despesas e receitas financeiras).

\subsection{Saldo da tesouraria $(T)$}

Além de ser calculado pela diferença entre o ativo e o passivo errático ( $T=A C F$ - $P C O)$, o saldo de tesouraria pode ser visualizado como sendo um valor residual obtido da diferença entre o capital circulante liquido e o investimento operacional em giro ( $\mathrm{T}=\mathrm{CCl}-\mathrm{IOG})$.

Em certas épocas do ano poderão surgir pressões de natureza sazonal que determinam a expansão do IOG. Nessas ocasiões sazonais que determinam a expansão do IOG. Nestas ocasiões T poderá torna-se negativo, uma vez que os levantamentos de empréstimos em curtos prazos e os descontos de duplicatas constituem fontes de financiamento adequadas para atender às necessidades temporárias de recursos.

Entretanto, se $C C L>O, I O G>O$ e $C C L<I O G$ configurar uma ação não transitória, T será cronicamente negativo, indicando o risco de insolência pelo fato da empresa estar financiando o IOG e/ou ativos permanentes como fundos onerosos de curto prazo.

\section{Configurações entre o CCL, o IOG e o T}

Considerando um conjunto de empresas, cada uma com um ativo total de $\$ 100$ (AT = ACF + ACC + ANC), cujo CCL e IOG variem entre $\$(20)$ e $\$ 20$, encontra-se o valor para $T(=C C L-I O G)$ constantes na tabela abaixo.

Quadro 5

Valores assumidos por $\mathrm{T}(\mathrm{em} \$)$

\begin{tabular}{|c|c|c|c|c|c|c|c|c|c|}
\hline $\mathrm{CCL} I O G$ & (20) & (15) & (10) & (5) & 0 & 5 & 10 & 15 & 20 \\
\hline$(20)$ & 0 & $(5)$ & (10) & $(15) ?$ & (20) & $?(25)$ & (30) & (35) & $(40)$ \\
\hline (15) & 5 & 0 & (5) & (10) & (15) & $i(20)$ & $\begin{array}{l}(25) \\
\text { Tipo }\end{array}$ & ${ }_{\text {IV }}^{(30)}$ & (35) \\
\hline (10) & ${ }^{10}$ Tipo & $\begin{array}{r}5 \\
V I\end{array}$ & 0 & (5)! & $(10)$ & (15) & (20) & (25) & $(30)$ \\
\hline (5) & 15 & 10 & & 0 & (5) & in & (15) & $(20)$ & (25) \\
\hline 0 & 20 & 15 & 10 & 5 & 0 & (5) & (10) & (15) & (20) \\
\hline 5 & 25 & 20 & 15 & $10:$ & 5 & 0 & (5) & (10) & $(15)$ \\
\hline 10 & 30 & $\begin{array}{l}25 \\
\text { Tipo }\end{array}$ & 20 & 15 & 10 & 5 & 0 & $\begin{array}{l}\text { Tipo } \\
\text { (5) }\end{array}$ & $\begin{array}{l}\text { III } \\
(10)\end{array}$ \\
\hline 15 & 35 & 30 & 25 & 20 & 15 & $\begin{array}{l}10 \\
\text { Tipo }\end{array}$ & $I I^{5}$ & $\circ$ & (5) \\
\hline 20 & 40 & 35 & 30 & 25 & 20 & 15 & 10 & 5 & 0 \\
\hline
\end{tabular}

Na prática seria muito remota a possibilidade de se encontrar o $C C L=0, I O G$ e o $C C L=I O G$. Assim, desprezando essas alternativas, pode-se localizar na tabela configurações que reflitam 6 tipos básicos de estruturas de balanços, cujas características são descritas a seguir

Tipo I 


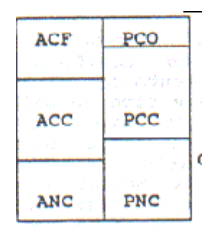

$\mathrm{CCL}>\mathrm{O}$ e $\mathrm{IOG}<\mathrm{O}=>\mathrm{T}>\mathrm{O}, \quad \mathrm{T}>\mathrm{O}$

Sendo $C C L>I O G=>T>C C L>I O G$.

$I O G<O$

Balanços com este tipo de estrutura refletem excelente liquidez, pois apresentam recursos permanentes aplicados no ativo circulante ( $\mathrm{PNC}>\mathrm{ANC} \rightarrow \mathrm{CCL}>\mathrm{O}$ ) e, conseqüentemente, boa folga financeira para honrar as exigibilidades de curto prazo $(A C>P C)$; Passivos de funcionamento maiores de que ativos circulantes operacionais ( $A C C<P C C \rightarrow I O G<O)$; e ativos circulantes financeiros excedendo aos passivos circulantes onerosos) (ACF $>\rightarrow T>0$ ).

Super mercados e empresas varejistas de artigos populares costumam apresentar balanços com a co figuração do tipo I, porque compram a prazo, giram rapidamente os estoques e vendem à vista.

Isto implicará em um ciclo financeiro muito reduzido ou até mesmo negativo. Na verdade por trás dessas atividades comerciais existe expressiva captação de recursos, fazendo com que as receitas financeiras tenham significativa participação na formação do lucro liquido. Nestas circunstancias, quanto maior for o volume de vendas, maior será o saldo positivo de tesouraria. Entretanto, se ocorrer queda brusca na vendas (devido à atuação da concorrência ou uma recessão econômica) T declinará rapidamente, podendo até transformar-se de positivo a negativo. Deste modo verifica-se que empresas com este tipo de balanço apresentam alto grau de sensibilidade às flutuações das vendas.

Os dirigentes destas empresas devem resistir a tentação de investir estas sobras de recursos em ativos permanentes , (expansão de redes de lojas, investimentos em outro ramo de negócios etc.), uma vez que os elevados saldos de tesouraria decorrem em grande parte de passivos de curtíssimo prazo precisam ser continuamente renovados.

O ciclo de produção e o prazo médio de cobrança tornam praticamente impossível encontrar empresas industriais com balanços deste tipo.

Tipo II

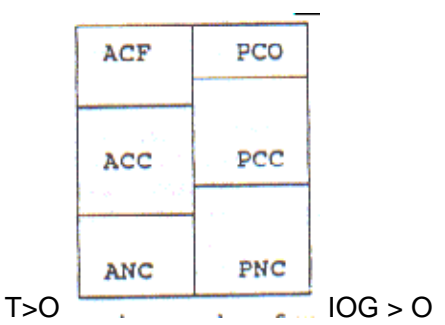

$\mathrm{CCL}>\mathrm{O}$ e $\mathrm{IOG}>\mathrm{O}$

Sendo $C C L>I O G \rightarrow T>O$,

$\mathrm{T}<\mathrm{CCL}$ e $\mathrm{T}=\mathrm{IOG}$

IOG positivo significa que os passivos de funcionamento (PCC) são insuficientes para atender as necessidades de financiamentos dos ativos operacionais de curto prazo (ACC).

Neste tipo de balanço, os recursos permanentes aplicados no capital de giro (CCL) suprem a insuficiência do PCC, e ainda permitem a manutenção de um saldo positivo de tesouraria.

O saldo positivo de tesouraria indica uma situação financeira sólida enquanto for mantido, determinado nível de operações. Entretanto, a expansão das vendas provocará o aumento do IOG e conseqüentemente redução do T. Se esta expansão for Sazonal, logo a empresa retornará à situação original (reforçada por um aumento no CCL decorrente da capitalização dos lucros adicionais). Por outro lado, um aumento grande e repentino das vendas fará com que o grande crescimento do IOG absorva todas as disponibilidades e demande novos empréstimos de curto prazo, tornando T negativo e, conseqüentemente, desestabilizado a estrutura financeira da empresa. 


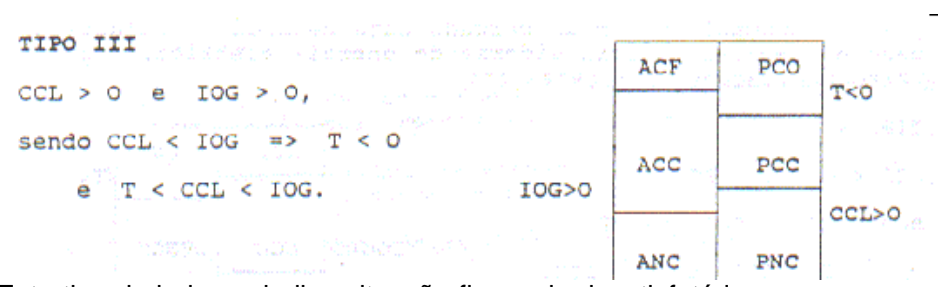

Este tipo de balanço indica situação financeira insatisfatória, uma vez que o CCL é inferior ao IOG. Empresas com este tipo de estrutura patrimonial são bastante dependentes de empréstimos de curto prazo para financiar suas operações.

O aumento da vulnerabilidade financeira ocorre à medida que cresce a diferença entre o CCL e o IOG e, conseqüentemente é ampliado o saldo negativo da tesouraria.

$$
\begin{aligned}
& \text { TIPO IV } \\
& \text { CCI }<0 \text { e IOG }>0 \Rightarrow T<0 \text {, } \\
& \text { sendo } \mathrm{CCL}<\mathrm{IOG} \Rightarrow \mathrm{T}<\mathrm{CCL}<\mathrm{IOG}
\end{aligned}
$$

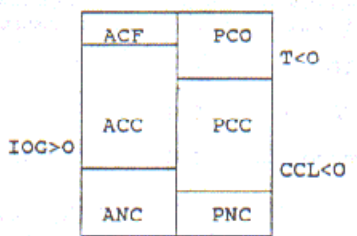

O CCL negativo indica que a empresa esta financiando ativos não circulantes com dividas de curto prazo $(P N C<A N C \rightarrow A C$ $<$ PC), relevando desequilíbrio entre as fontes e as aplicações de recursos. Isto seria suficiente para configurar uma situação financeira ruim e restringir o acesso da empresa às fontes de financiamento de curto prazo. Entretanto, mesmo com o CCL negativo, poderia ocorrer da empresa continuar obtendo crédito junto aos seus fornecedores e levantar empréstimos bancários. Isto aconteceria mediante ao oferecimento de garantias adicionais, tais como: aval de proprietários detentores de grandes fortunas, solidez do grupo econômico a que pertence a empresa, conceito crediticio dos sacados das duplicatas descontadas ou dadas em garantia etc.

Neste tipo de balanço deve-se ressaltar que a ocorrência simultânea de IOG positivo do CCL negativo indica péssima situação financeira, com a possibilidade de agravamento com a expansão dos negócios, evidenciado pelo crescimento do saldo negativo de tesouraria.

Empresas privadas com este tipo de balanço estariam à beira da falência, a menos que seus acionistas controladores pudessem fornecer-lhe algum tipo de apoio externo.

Essa configuração aparece com a maior freqüência em empresas estatais mal administradas, com preços ou tarifas defasados etc.

Essas estatais sobrevivem graças às periódicas injeções de recursos realizadas pelo seu acionista majoritário (governo federal estadual ou municipal) e também por poderem contar com um fluxo regular de receitas operacionais face ao fato de deterem posição monopolista em um mercado cuja demanda é inelástica. E o caso de empresas distribuidoras de energia elétrica, empresas de telecomunicações, ferrovias e etc.

$$
\begin{aligned}
& \text { TIPO } \nabla \\
& C C L<0 \text { e IOG }<0, \\
& \text { sendo } C C I<I O G \Rightarrow \mathrm{T}<0, \\
& \quad \mathrm{~T}>\mathrm{CCL} \text { e } \mathrm{T} \text { 市 IOC. }
\end{aligned}
$$

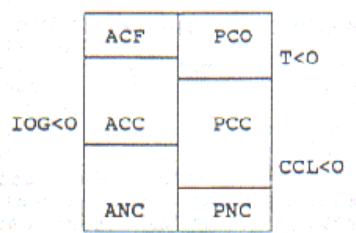

Neste tipo de balanço a situação financeira é muito ruim, porém menos grave do que o tipo IV devido ao fato dos passivos de funcionamento excederem às necessidades de recursos para financiar os ativos circulantes operacionais $(A C C<P C C \rightarrow I O G$ $<$ O). Isto atenua os efeitos negativos sobre o saldo de tesouraria.

$$
\begin{aligned}
& \text { TIPO } \nabla I \\
& \text { CCI }<0 \text { e IOG }<0, \\
& \text { sendo } C C I>I O G \Rightarrow T>0 \\
& \text { e } \mathrm{T}>\mathrm{CCL}>\text { IOG. }
\end{aligned}
$$

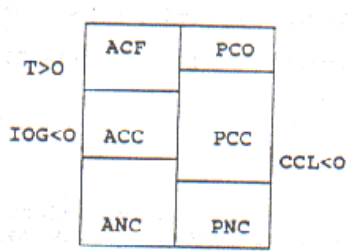

Este tipo de balanço revela que a empresa estaria desviando sobras de recursos de curto prazo para ativos não circulantes e mantendo um saldo positivo de tesouraria. Uma situação como esta não poderia ser mantida por muito tempo, pois uma queda no volume de vendas esgotaria rapidamente a parcela excedente do PCC, invertendo o sinal do IOG e do saldo de tesouraria. 
Trata-se de um tipo de configuração que envolve alto risco de insolvência.

\section{$2.4 \mathrm{IOG} \times \mathrm{XCFe}$}

O montante de recursos necessários para financiar o IOG (positivo) é afetado pelas receitas de vendas, pelo ciclo financeiro e pelos saldos de outras contas cíclicas que não integram ao ciclo financeiro, como segue:

$I O G=$ CFe $x$ ROB - DA

Onde,

$\mathrm{CF}$ e $=$ PmeEmp + PmeEpm + PmeEpa + PMC - PmePf (prazos médios equivalentes expressos em dias de vendas):

ROB - DA = receitas brutas de vendas diminuídas das devoluções e abatimentos sobre vendas;

$\mathrm{ROB}-\mathrm{DA} / 360$ = receitas médias diárias de vendas;

CFe $\times(R O B-D A / 360)=$ recursos aplicados nos estoques e nas duplicatas a receber deduzidos dos financiamentos dos fornecedores.

OCC = Outras contas cíclicas: diferença entre saldos das contas do ACC, inclusive Estoques e Duplicatas a Receber, e os saldos das contas do PCC, inclusive Fornecedores.

Conhecendo antecipadamente o valor do IOG, da receitas de vendas e do diferencial entre as outras contas cíclicas, pode-se determinar o ciclo financeiro equivalente, a partir da formula anterior, a saber

$\mathrm{CFe}=\frac{\mathrm{IOG}+-\mathrm{OCC}}{\mathrm{ROB}-\mathrm{DA} / 360}$

Note a inversão dos sinais relativos às outras contas cíclicas (OCC), no calculo do valor do IOG, quando os outros arquivos circulantes cíclicos forem maiores do que os outros passivos circulantes cíclicos, o OCC será positivo e deverá ser somado; quando o OCC for negativo deverá ser subtraído. No calculo do CFe quando OCC for positivo deverá ser subtraído e se for negativo ser somado.

\subsection{Autofinanciamento da expansão do IOG}

A análise das possíveis configurações entre o CCL, o IOG e o T evidenciou que uma situação financeira sólida implica na manutenção de CCL positivo e maior do que o IOG. Desta forma ocorrendo IOG positivo, o CCL seria suficiente para financia-lo e ainda gerar um saldo positivo de tesouraria (CCL>O, IOG > O, CCL > IOG e T > O).

Para que a expansão do IOG (positivo) não prejudique a situação financeira da empresa será necessário que oCCL também aumente.

Os lucros retidos (lucros líquidos - dividendos) permitirão expandir o $\mathrm{CCL}$, desde que tais recursos gerados internamente não sejam desviados para o financiamento de novos ativos não circulantes (ANC $=R L P+A P)$. Assim se a empresa captar exatamente recursos próprios ou recursos de terceiros em longo prazo em montante o suficiente para financiar as aquisições de ativos permanentes, os recursos gerados pelas operações poderão ser integralmente reaplicados no capital de giro.

Para determinar o valor dos fundos incorporados ao CCL, deve-se adicionar aos lucros retidos as despesas de depreciação,amortização e exaustão que foram recuperadas nas receitas de vendas, mas não representaram utilização de CCL. Na DOAR estas despesas são somadas ao lucro liquido pela mesma razão e os dividendos aparecem como aplicação do CCL.

Dentro das premissas acima, o autofinanciamento do IOG, apresenta o seguinte mecanismo ou seqüência. 


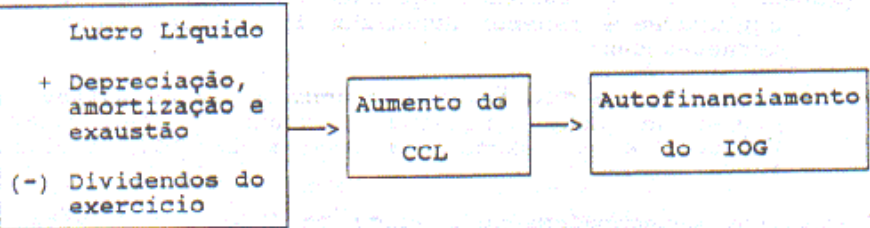

A seguir é apresentado um exemplo onde a expansão das vendas não afetou o ciclo financeiro equivalente e foi financiada através do reinvestimento integral dos lucros retidos + depreciação.

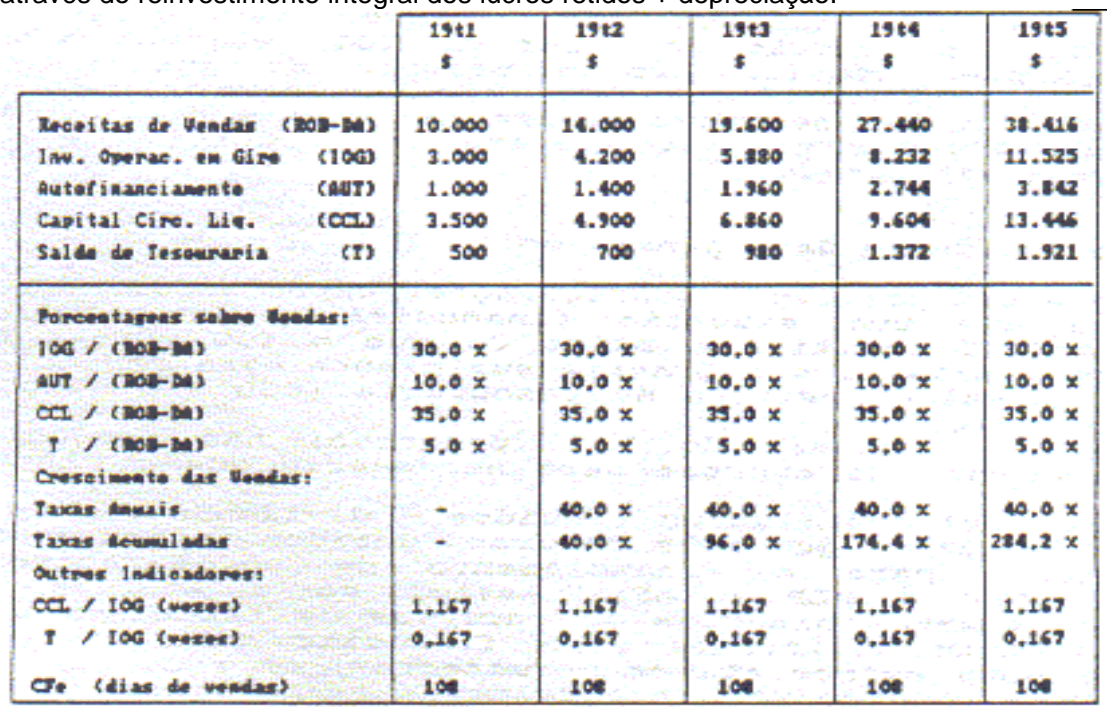

Observa-se que o substancial crescimento do IOG não afetou a boa situação financeira existente em 1971 (balanço do tipo II).

Apesar das vendas terem crescido à taxa de $40 \%$ ao ano, foram mantidas as proporções originais do CCL, do IOG e do T, em relação às receitas de vendas. Também não houve alteração nas relações "CCL /IOG" e "T / IOG" e CFe foi mantido (admitiu-se que o OCC foi igual a zero).

Para alcançar essa expansão nas vendas, a empresa certamente teria ampliado a sua planta industrial. Como não ocorreram modificações na estrutura dos elementos envolvidos com o capital de giro, deduz-se que os investimentos adicionais no ativo não circulante foram realizados mediante aporte de recursos de longo prazo captados externamente, tais como: lançamento de novas ações e/ou de debêntures, obtenção de financiamento em longo prazo para a compra de equipamentos etc. É claro que a rentabilidade das operações deveria ser suficiente atraente para viabilizar a captação desses novos recursos permanentes.

Além da qualidade dos produtos, do padrão de serviços oferecidos aos clientes (assistência técnica etc.) e das campanhas publicitárias, a expansão das vendas poderá basear-se no oferecimento de preços competitivos e de maiores prazos para pagamento.

A redução nos preços de venda afetará o lucro bruto, mas provavelmente ocorreria maior absorção das despesas operacionais fixas que, crescendo menos que as receitas de vendas, beneficiaria o resultado contábil pelo efeito de alavancagem operacional.

Por outro lado, o aumento das despesas de depreciação decorre da aquisição de novos ativos fixos poderia fazer com que a porcentagem do autofinanciamento sobre as vendas permanecesse praticamente igual àquela obtida na posição original do exemplo anterior (1971). Em outras palavras, a queda no lucro liquido devida a redução nos preços de venda seria compensado com a adição do maior valor das despesas de depreciação.

$-0-$

No próximo exemplo a expansão das vendas foi promovida pela concessão aos clientes de maior prazo para pagamento e isto refletiu no aumento do ciclo financeiro equivalente. O IOG aumentou devido ao maior volume de vendas e à dilatação do CFe (admitiu-se OCC += zero).

O crescimento das vendas observou as seguintes condições restritivas: 
1) O aumento do IOG não poderia ultrapassar a capacidade de autofinanciamento, podendo ser utilizado o saldo positivo de tesouraria existente em 1971;

2) O CCL não poderia ser inferior ao IOG e T não poderia tornar-se negativo.

Partindo da posição de 1971 e considerando que o autofinanciamento corresponda a $10 \%$ das receitas de vendas, pretende-se conhecer até que ponto as vendas poderão expandir às custas da ampliação dos prazos médios de cobrança e, por decorrência, do aumento do CFe.

Quadro 7

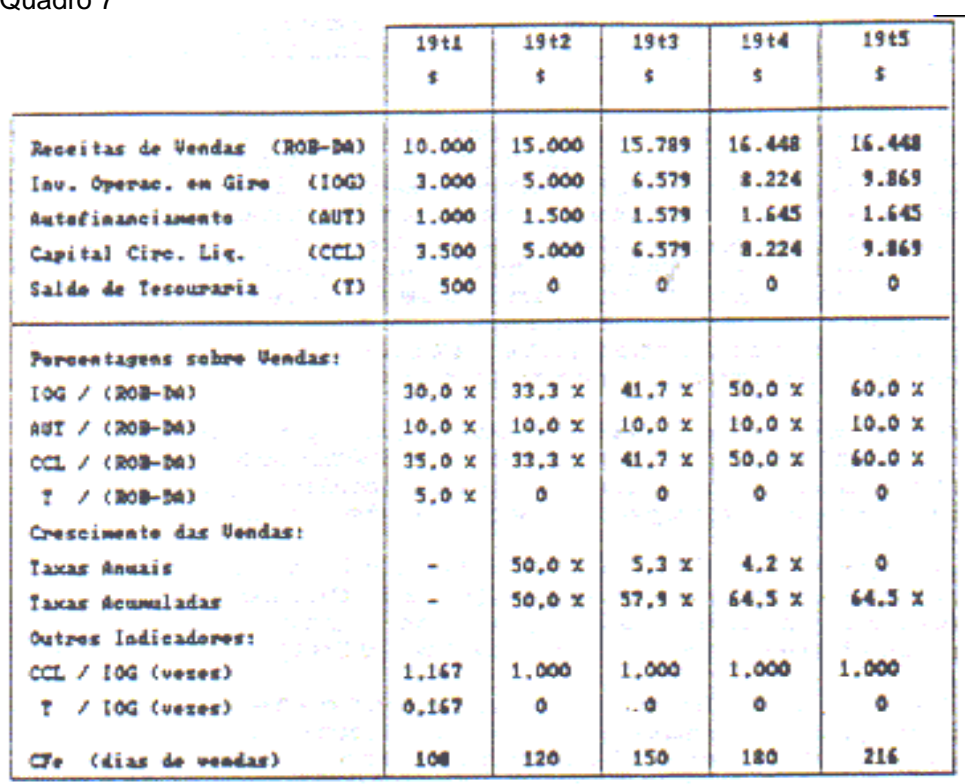

Já em 1972 a situação financeira decaiu ligeiramente devido à utilização do saldo de tesouraria positivo existente em 1971 mas como o CCL não ficou abaixo do IOG a situação financeira continuaria satisfatória.

A partir de 1973 as taxas de crescimentos das vendas tornaram-se irrisórias, pois se haviam incentivos aos clientes representados pela ampliação do prazo para pagamento, por outro lado havia restrições relativas à observação dos limites do autofinanciamento. E. 1975, mesmo com a expansão do CFe, as vendas não apresentaram crescimento devido às restrições estabelecidas "a priori".

\section{6 "Overtrade" O Efeito Tesouraria}

O "Overtrade" acontece quando uma empresa expande significativamente o nivekl de operações e vendas, sem o desvio suporte de recursos para financiar o decorrente aumento do capital de giro. (2)

Uma empresa que esteja operando com capacidade ociosa em sua planta industrial poderá desejar um aumento na produção e vendas visando obter redução nos custos de produção devido às economias de escala. Isto provocará aumento nos estoques, nas duplicatas a receber e nas duplicatas a pagar aos fornecedores. Se os prazos médios de estocagem, de cobrança e de pagamento forem mantidos haverá um crescimento acentuado no IOG (positivo) que poderá rapidamente ultrapassar o CCL por insuficiência de recursos provenientes do autofinanciamento. Nestas condições estaria ocorrendo o "overarte".

Ac Expressão efeito tesoura, adotada por Fleuriet, corresponde à representação gráfica da evolução das vendas, do IOG, do CCL e do T em situações de IOG através de créditos de curto prazo não renováveis automaticamente, como são as operações de financiamento que integram o passivo circulante oneroso. Neste caso, o saldo da tesouraria apresenta-se negativo com a taxa de crescimento superior à do IOG.

Os seguintes fatos caracterizam o efeito tesoura em uma empresa:

As vendas crescem a taxas anuais elevadas;

A relação "IOG / (ROB-DA)" durante o período do crescimento das vendas, admitindo que ambas as relações sejam positivas. 
Durante o período de crescimento das vendas, as fontes externas que aumentam o CCL são utilizadas somente para novos investimentos em bens do ativo permanente.

A representação gráfica do efeito tesoura encontra-se na figura a seguir. Até o quarto ano, a empresa representava $C C L>$ 0 , IOG > o, sendo CCL>IOG e T >0. No quinto ano o CCL igualou-se ao IOG (ambos positivos) e T tornou-se nulo. A partir do sexto ano, verifica-se que o CCL é sempre inferior ao IOG e T apresenta-se negativo. Deste modo, o efeito tesoura ocorreu a partir do quinto ano.

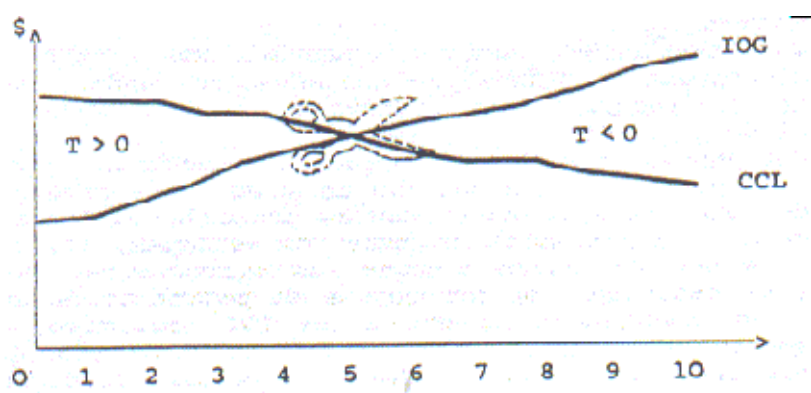

A mecânica do efeito tesoura é apresentada no exemplo a seguir em que as vendas dobram em cada ano, conservando o CFe original e as proporções do IOG e do AUT sobre as receitas de vendas. O CCL aumenta os valores absolutos, porém diminui a sua proporção em relação às vendas e ao IOG. O saldo de tesouraria passa de positivo a negativo e a relação "T/IOG" cresce negativamente (admitiu-se OCC = zero).

\begin{tabular}{|c|c|c|c|c|c|}
\hline & 19t1 & $\begin{array}{c}19+2 \\
3\end{array}$ & 1960 & $\begin{array}{c}1914 \\
\text {, }\end{array}$ & $19+5$ \\
\hline Mecelitas de Mandas (mol-din) & 10.000 & 20.000 & $40 . \infty 0$ & 80.000 & 160.000 \\
\hline [av. oprae. on Gire $(1 \infty)$ & $3 . \infty 00$ & 6.000 & 12.000 & 24.000 & $40 . \infty \infty$ \\
\hline Autof in anci aneate & $1 . \infty 00$ & 2.000 & 4.000 & 1.000 & 16.000 \\
\hline cagital cise. bif. & 3.300 & 5.500 & 9.500 & 17.500 & 33.500 \\
\hline salco to tesoeruria & 300 & $(5 \infty)$ & $(2.500)$ & $(6.500)$ & (14.500) \\
\hline Moneatanes soline reseas: & & & & & \\
\hline $100 /(200-10)$ & $30,0 \times$ & $30,0 x$ & $30,0 \times$ & $30,0 \times$ & $30,0 \times$ \\
\hline$\omega \pi /(n 0 t-m)$ & $10,0 \times$ & $10,0 \times$ & $10,0 \times$ & $10,0 \times$ & $10,0 \times$ \\
\hline $\operatorname{coc} /(\operatorname{mos}-m)$ & $35,0 \times$ & $27,5 \times$ & $23,79 x$ & $21,9 x$ & $20,9 x$ \\
\hline$i /(\mathbf{m}-\mathbf{n})$ & $5,0 \times$ & $(2,5) x$ & $(6,25) x$ & $(\mathbf{a}, 1) x$ & $(9,1) \times$ \\
\hline Oessoimeto Las Voedas: & & & & & \\
\hline Taxas Anvais & - & $100 \times$ & $100 x$ & $100 \times$ & $100 x$ \\
\hline Taxas devmentadas & - & $100 \times$ & $300 x$ & $700 x$ & $1.500 x$ \\
\hline Cutros Indicadores: & & & & 0.729 & 0.698 \\
\hline $\begin{array}{l}c a, / 106 \text { (veris) } \\
t / 100 \text { (veres) }\end{array}$ & 0.167 & $(0,083)$ & $(0,200)$ & $(0,271)$ & $(0,300)$ \\
\hline O. (Jias de vendas) & 108 & เ⿳⺈ & 200 & 10 & 10 \\
\hline
\end{tabular}

Em 1971 a empresa apresentava uma estrutura de balanço do tipo II e a partir de 1972 a estrutura passou para o tipo III.

Neste momento em que o IOG suplantou o CCL e T passou a ser negativo, iniciou-se o efeito tesoura.

Embora o CCL tenha permanecido sempre positivo, o crescimento do saldo negativo de tesouraria mostra um aumento da dependência de empréstimos de curto prazo para financiar o IOG.

Isto evidencia a deterioração da liquidez, e provavelmente, da rentabilidade (face ao crescimento das despesas financeiras). Os credores passarão a considerar a empresa como sendo um "mau risco linhas de crédito bancário, além de se tornarem mais difíceis, envolveram taxas de juros cada vez mais altas".

\subsection{Exemplo com um Caso Real}

A seguir são apresentados alguns índices financeiros convencionais calculados a partir dos balanços do quadro 1

\section{Quadro 9}




\begin{tabular}{|c|c|c|c|}
\hline & & $19+8$ & $19+9$ \\
\hline Capital de $3^{\circ} \mathrm{s} /$ Capital proprio & $(P C+E L P / P L)$ & 42,18 & 58,98 \\
\hline Composiçáo do endividamento & $(\mathrm{PC} / \mathrm{PC}+\mathrm{ELP})$ & $72,2 \%$ & 81,08 \\
\hline Endividamento geral & $(P C+E L P / A T)$ & 29,58 & 37,08 \\
\hline Imobilizaçào dos rec.permanentes & (AP/ELP+PL) & 42,76 & 49,98 \\
\hline Liquidez geral & $(A C+R L P / P C+E L P)$ & 2,26 & 1,76 \\
\hline Liquidez corrente & $(A C / P C)$ & 3,09 & 2,14 \\
\hline Liquidez seca & $(A C-E S T-D E S / P C)$ & 1,86 & 1,06 \\
\hline
\end{tabular}

Todos os índices apresentam desfavorável e os dois primeiros despertariam alguma preocupação. Apesar disto os outros índices ainda estão muito bons em 1979.

Dificilmente alguém faria restrições à situação financeira deste grande grupo industrial de capital nacional. A empresa controladora deste grupo é de capital aberto e suas ações são bastante negociadas em bolsa.

Entretanto, a visão limitada oferecia pelos índices apresentados não permite detectar aspectos de certa gravidade relativos à situação financeira que aparecem nitidamente com a análise da configuração entre $\circ \mathrm{CCl}, 0 \mathrm{IOG}$ e $\circ \mathrm{T}$ a seguir desenvolvida.

No quadro 10 verifica-se que em 1978 a situação financeira estava muito boa (balanço do tipo II) e nem em 1979 o grupo industrial passou a apresentar uma situação financeira insatisfatória (balanço do tipo III).

O expressivo aumento das receitas de vendas $(47,7 \%)$, associado à pequena redução no ciclo financeiro equivalente (de 120,5 para 115,8 dias de vendas) e ao aumento do diferencial negativo do OCC (de $\$ 392.956$ para $\$ 588.228$ ), fizeram com que o IOG crescesse menos do que as vendas (40\%).Desta forma, a porcentagem do IOG sobre as receitas de vendas declinou ligeiramente (de $26,7 \%$ para $25,3 \%$ ).

O CCL apresentou pequena queda $(-7,8 \%)$ provocada pelo reduzido valor do autofinanciamento $(3,2 \%$ sobre as vendas em 1979) e pela transferência de recursos de capital de giro para ativos não circulantes. Com isto, a porcentagem do CCL sobre vendas caiu de forma acentuada (de $33,6 \%$ para $21 \%$ ).

Esses fatos fizeram com que o saldo de tesouraria passasse de positivo em 1978 para negativo em 1979, evidenciando dependência no uso de empréstimos de curto prazo para financiar as operações correntes.

Quadro 10 


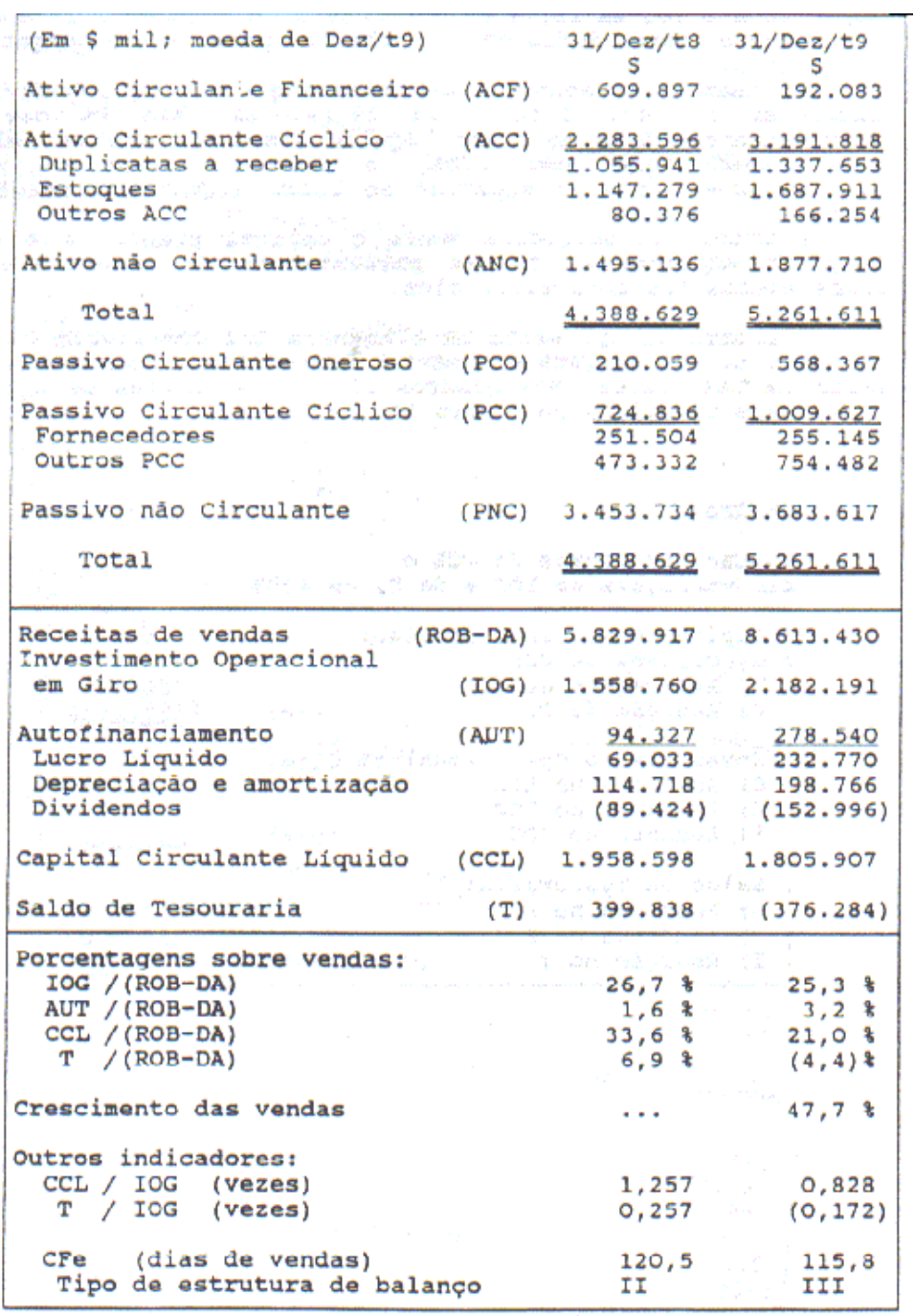

Visto por outro ângulo, tem-se que em Dez/78 o CCL, ficou 17,2\% abaixo do IOG, sendo esta deficiência coberta pelo saldo negativo de tesouraria.

Um dado interessante a destacar é que em 1978 os dividendos excederam o lucro liquido em 29,5\%, em 1979 os dividendos representaram $65,7 \%$ do lucro liquido. Isto se explica pelo fato de nestes dois exercícios, o lucro liquido da empresa controladora ter sido superior ao lucro liquido consolidado do grupo.

A fraca rentabilidade sobre o capital próprio e o elevado "payout" explicam as baixas porcentagens do auto financiamento sobre vendas nos dois exercícios.

O Quadro 11 apresenta os elementos que compuseram os fluxos do CCL e do IOG em 1979 e "amarra" esses fluxos com a variação do saldo de tesouraria. Nos quadros 12 a 14 encontram-se detalhados os valores resumidos no quadro 11.

Quadro 11

Resumo dos Fluxos do CCL e das variações do IOG e do T, em 1979. 


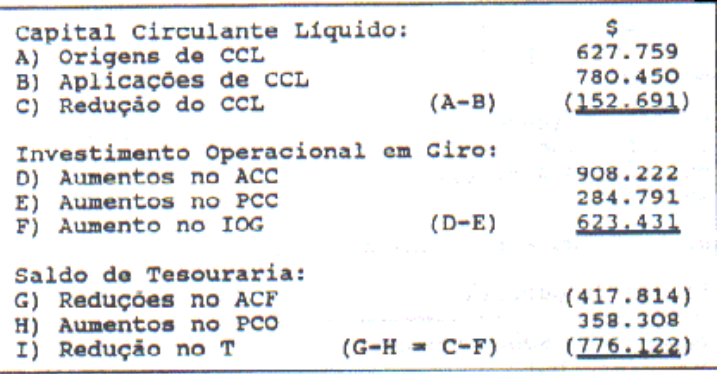

Quadro 12

Demonstração das origens e Aplicações de Recursos em 1979

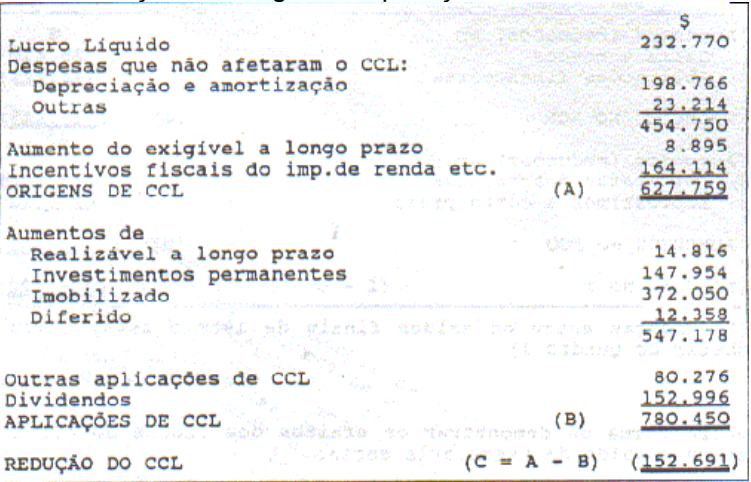

(Valores extraídos da DOAR publicada)

Quadro 13

Demonstração das Variações no Investimento Operacional em Giro em 1979

\begin{tabular}{|c|c|}
\hline $\begin{array}{l}\text { Aumentos em } \\
\text { Duplicatas a receber } \\
\text { Estoques } \\
\text { Outros ACC }\end{array}$ & $\begin{array}{r}\$ \\
281.712 \\
540.632 \\
85.878 \\
\end{array}$ \\
\hline AUMENTOS NO ACC & 908.222 \\
\hline $\begin{array}{l}\text { Aumentos (reduçōes) em } \\
\text { Fornecedores } \\
\text { Imposto sobre vendas } \\
\text { Contas a pagar } \\
\text { Salários e encargos sociais } \\
\text { Prov. p/imp.de renda e contribuição social } \\
\text { Dividendos a pagar }\end{array}$ & $\begin{array}{r}3.641 \\
103.737 \\
101.097 \\
39.428 \\
38.406 \\
(1.518) \\
\end{array}$ \\
\hline AUMENTOS NO PCC & 284.791 \\
\hline AUMENTOS NO IOG & 623.432 \\
\hline
\end{tabular}

Quadro 14

Demonstração das variações no saldo de tesouraria em 1979

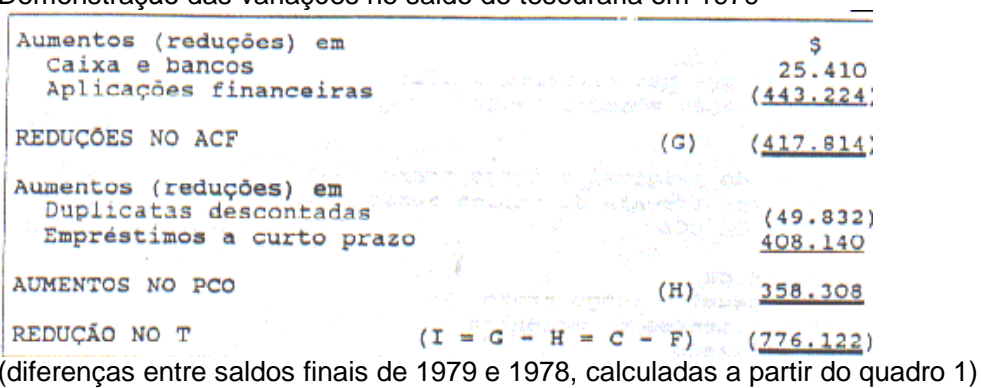

Outra forma de demonstrar os efeitos dos fluxos do CCL e do IOG sobre o saldo de tesouraria seria: 
Quadro 15

Fatores Determinantes da variação do saldo de tesouraria, em 1979

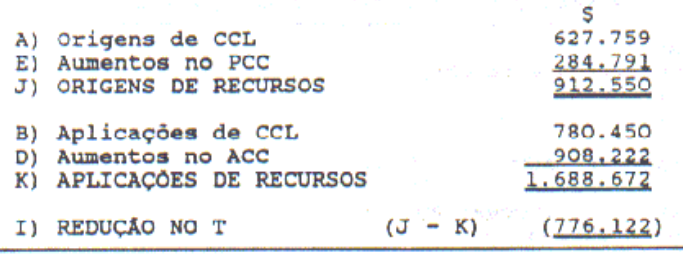

\section{Conclusão}

As ferramentas tradicionais de análise de balanços, constituídas por índices financeiros e pelas porcentagens das análises vertical e horizontal, mostram apenas posições estáticas verificadas nas demonstrações contábeis. As limitações deste instrumental geram mais dúvidas do que a certeza e a superficialidade das informações obtidas por estes meios convencionais torna temerária a inferência sobre a situação futura das empresas analistas.

Neste trabalho apresentamos um modelo de análise que fornece explicações completas e articulares sobre as causas das modificações ocorridas na situação financeira das empresas. Dispondo apenas das demonstrações financeiras publicadas na imprensa é possível avaliar rapidamente as situações financeiras refletidas nos dois últimos balanços (tipo i e VI). As causas determinantes da evolução da situação financeira no ultimo exercício social serão encontradas através do fluxo de capital circulante liquido, do investimento operacional em giro e do saldo da tesouraria, conforme demonstrado nos quadros 10 e 15. Essas informações são de grande utilidade tanto para os administradores, quanto para os diversos agentes externos que estejam interessados em avaliar a saúde financeira da empresa (credores em geral, concorrentes, acionistas minoritários etc.)

Em termos gerenciais, o modelo permite projetar o montante de recursos necessários para compor o capital de giro operacional (quadro 4) e realizar simulações sobre a situação financeira no futuro (quadros 6 a 8).

Bibliografia

Assaf Neto, Alexandre. Estrutura e Análise de Balanços um enfoque econômico-financeiro. 3 ed., São Paulo, Atlas, 1987

Braga, Roberto. Fundamentos e Técnicas de Administração Financeira. São Paulo, Atlas, 1989.

Brasil, Haroldo V. \$ Fleuriet, Michael. O Planejamento das Pequenas e Médias Empresas; um modelo integrado.2.ed.Contagem,Seculus Editora Ltda. E Edições Fundação Dom Cabral, s.d.

Fleuriet, Michael e outros. A Dinâmica Financeira das Empresas, um novo método de análise, orçamento e planejamento financeiro. 2 ed., Belo Horizonte, Edições Fundação Dom Cabral e Consultoria Editorial Ltda., 1980.

Matarazzo, Dante C. Análise Financeira de Balanços . 2.ed., São Paulo, Atlas, 1987, 2v.

Oliquenvitch, José L. \$ Santi Filho, Armando de Análise de Balanços para controle Gerencial, enfoque sobre o fluxo de recursos e previsão de rentabilidade. São Paulo, Atlas, 1987.

Silva, José Pereira da. Análise Financeira das Empresas. São Paulo, Atlas, 1988. 